\title{
Extraction of Collapse Risk Factors for Operation-Road in Terasawayama Forest
}

\author{
Masashi Saito $^{1 *}$, Daisuke Shindo ${ }^{1}$, Wataru Kinoshita ${ }^{1}$, Tatsuhito Ueki ${ }^{1}$, Hiroshi Inoue ${ }^{1}$
}

Abstract:

High-density road networks, including established operation-roads, are necessary for mechanized forestry. However, operation-roads and forest roads are typically constructed using different methods. For example, surface processing and the creation of retaining walls are often omitted from the construction of operation-roads to keep costs low, even though such omissions can increase the risk of collapse due to heavy rainfall. Previous studies have clarified the factors that can cause the collapse of forest roads; however, these risks factors remain unknown for operation-roads. To address this, we attempted to extract estimates of the collapse risk for operation-roads with reference to previous studies regarding forest roads. In particular, we extracted the factors resulting in high risk of collapse (i.e., terrain conditions, the geometric structure of the collapse point) based on the operation-road patrol record. Numeric values in the range 0-1 were used to express the determined collapse risk based on the concept of fuzzy theory. Finally, a comparison of the importance of the various contributing factors was conducted using mathematical quantification type II. The results demonstrate that the geometric structure of the collapse point is the dominant factor controlling the collapse risk of operation-roads, in contrast to forest road collapse, which is induced primarily by unfavorable terrain conditions.

Keywords: collapse factor, forest road, operation-road, road collapse

\section{Introduction}

The construction of forest road networks is essential for forest management, as such construction allows the passage of forestry machinery and vehicles. In particular, road networks help improve the efficiency of forestry management because they reduce the cost of production. Accordingly, the construction of forest road networks has been promoted actively in Japan.

Forest road networks can be divided into operation-roads and forest roads, the former of which are typically of a lower standard. Typically, operation-roads are intended to be used for forestry, without requiring the passage of general vehicles, which allows operation-roads to be constructed at lower cost than forest roads. In Japan, the forest road network density is $12.9 \mathrm{~m} /$ ha for forest roads, but only $3.9 \mathrm{~m} /$ ha for operation-roads, and the current density of operation-roads is insufficient for current forestry requirements. This may be attributed, at least in part, to the more extensive literature available regarding construction techniques for forest roads than for operation-roads (Suzuki and Yamauchi, 2000).

To build stable operation-roads, it is essential to clarify the factors controlling collapse of operation-roads and to investigate appropriate techniques for their construction. In contrast to forest roads, operation-roads do not incorporate surface processing or retaining walls, resulting in increased risk of collapse in response to rainfall. However, in general, the factors leading to collapse of forest roads have been well studied (e.g., Yoshimura et al., 1995; 1996; Kondo and Kamiya, 1995), whereas those for operation-roads have not. To address this, in the present study, we extracted information about the factors controlling the collapse risk for operation-roads using fuzzy theory, determined the most important factors using mathematical quantification theory class II, and compared our results to those of previous studies for forest roads.

\section{Study Site}

This study site was the Shinshu University Terasawayama Forest in Nagano Prefecture, Japan. This forest is located to the east of Ina City. The site lies at altitudes of 950-1450 m within the headwaters of the Tanazawa River, which is a tributary of the Tenryu River. The geology is primarily hornfels and Takato granite, which belong to the Ryoke metamorphic rocks.

The study area experiences a relatively cold climate, with an annual average temperature of $7.9^{\circ} \mathrm{C}$ and a minimum temperature of $-17.5^{\circ} \mathrm{C}$. Snow depth can reach approximately $30 \mathrm{~cm}$, and

Received Aug.12, 2014; Accepted Feb.5, 2015; J-STAGE Advance Published Date: Feb.20, 2015

${ }^{1}$ Faculty of Agriculture,Shinshu University, Japan,

*Corresponding Author:m_saito@shinshu-u.ac.jp 
the frost-free period lasts about 4.5 months. The forest vegetation comprises primarily Japanese red pine, Japanese larch, and Japanese cypress, with planted forest making up approximately $95 \%$ of all forest. A road network with relatively high density has been established: the total route length is $17,961 \mathrm{~m}$, and the road network density is $78.28 \mathrm{~m} /$ ha. Data describing collapse-related disasters in Terasawayama Forest exist from 2011 onward, for a total of 33 locations (21 and 12 locations for slope and road shoulder collapse, respectively).

\section{Methods}

\subsection{Collapse Risk Assessment Method}

Based on the form of damage incurred, operation-road collapse can be divided into three types: slope collapse, shoulder collapse, and scouring of the road surface. In the present study, we surveyed slope collapse and shoulder collapse (Figure 1); however, we omitted road surface scour because it is strongly influenced by drainage function and rainfall.
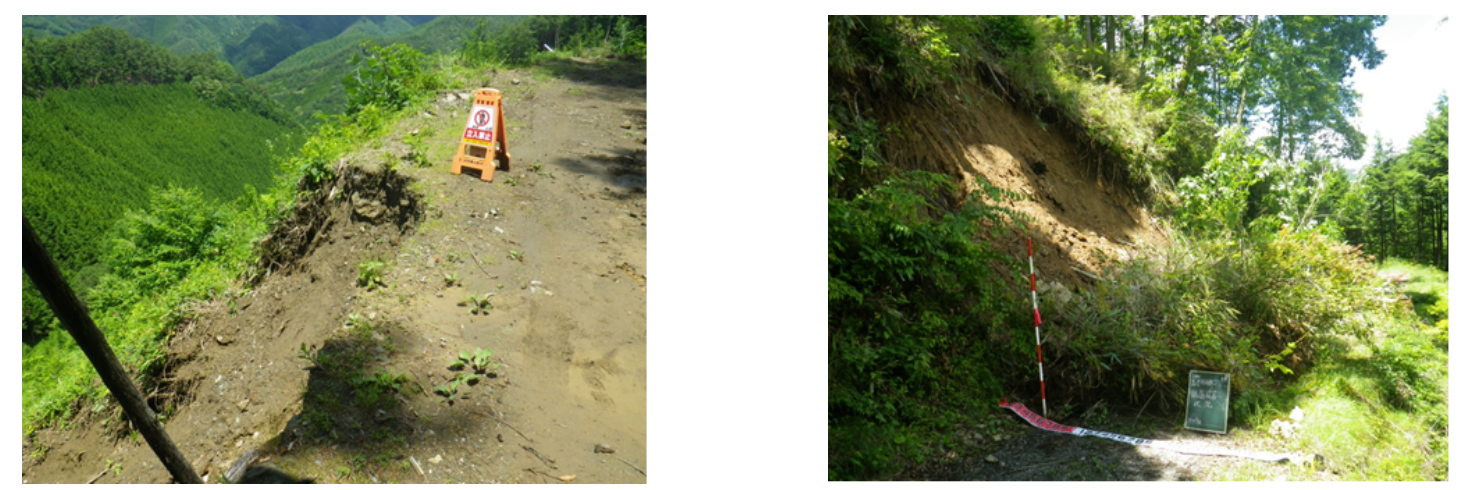

Figure 1. Examples of road collapse (Left: Shoulder collapse of the valley side. Rigth: Slope collapse of the mountain side)

It is thought that the factors causing collapse are different for shoulder collapse and slope collapse. Therefore, we assessed collapse risk using 11 factors, which we categorized according to fuzzy theory. By the way, that the collapse occurs rainfall becomes the incentive is mostly in operation-road collapse. However, since it is intended to clarify the cause of an operation-road unbreakable. The study area is small in this study, were excluded from the factor since it is considered rainfall of the study area as being the same amount.

Table 1. Surveyed factors affecting operation-road collapse.

\begin{tabular}{cc}
\hline Terrain conditions & Geometric structure \\
\hline Catchment area & Cut and fill slope height \\
Natural ground angle & Cut and fill slope length \\
& Cut and fill Slope angle \\
& Width \\
& Longitudinal slope \\
& Crossing gutter interval \\
\hline
\end{tabular}

Table 1 shows the factors surveyed. These factors were chosen for two primary reasons: they have been investigated previously for forest roads, thus allowing comparison; and they are considered highly versatile metrics for investigation. A definition and examination method of a factor is shown below. 
1) Catchment area: The catchment area of research point of collapse and non-collapse We calculated in GIS. By using the DEM of $10 \mathrm{~m}$ mesh publishes GSI and calculate the value of catchment area by using the topographical analysis function of GIS. The minimum value of the catchment area I was $1000 \mathrm{~m}^{2}$.

2) Natural ground slope: The slope of the ground slope using a hand level is shown in Figure 2 was measured.

3) Cut slopes height, fill slopes height: The vertical height of the cut side slopes and the fill side slopes for each survey point was measured by pole surveying.

4) Cut and fill slope length cut and fill slope angle: Measuring the vertical and the horizontal length of the slope when measuring the slope height pole survey was calculated from the result.

5) Width: The total width of shoulder as also including that shown in Figure 1 was surveyed. The width of each survey point was measured with use a tape measure $10 \mathrm{~cm}$ unit.

6) Longitudinal gradient: The gradient away back and forth about the survey points by $10 \mathrm{~m}$ using a hand levels were measured.

7) Crossing gutter interval: We recorded all placement location Crossing gutter drainage when the field survey. Was then calculated the distance to the Crossing gutter in the upper part of survey points using the distance measuring function of the GIS

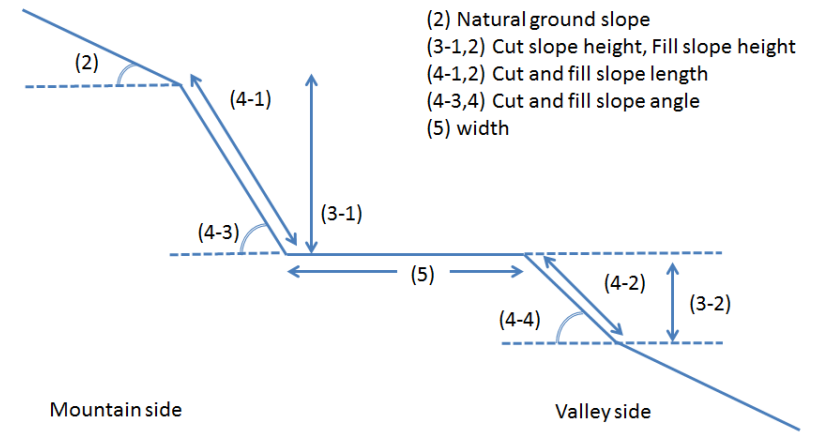

Figure 2. Measurement method of cross-section.

\subsection{Factor Categories}

It is necessary to assign each factor a numeric value in order to understand changes in the collapse risk associated with changes in the controlling factors. In the present study, we categorized each factor according to three different methods (Table 2).

Table 2. Methods of categorizing factors.

\begin{tabular}{ccc}
\hline Forest road regulations & Terrain conditions & Geometric structure \\
\hline Width & Cut and fill slope height & Catchment area \\
& Cut and fill slope length & Crossing gutter interval \\
& Cut and fill slope angle & \\
& Natural ground angle & \\
& Longitudinal slope & \\
\hline
\end{tabular}

Standard deviation classification involves determining a threshold with reference to the standard deviation of the data set from the average value, whereas natural classification involves setting the 
threshold according to relatively large fluctuations that occur within the data set. In the present study, road width was determined by forest road regulations; accordingly, no further classification was required for this parameter. However, as they have not been defined explicitly by existing legislation, the remaining factors were classified according to standard deviation classification techniques, or by using natural classification when standard deviation classification was deemed unsuitable. Thus, cut and fill slope height, slope length, slope angle, natural ground angle, and longitudinal slope were categorized using standard deviation classification, and catchment area and crossing gutter interval using natural classification.

Natural classification was adopted for catchment area and crossing gutter interval because these parameters exhibited considerable variability, such that their means were unrepresentative of the data sets overall. For example, for catchment area, about $80 \%$ of the data indicated values of $1,000 \mathrm{~m}^{2}$ or less, with only $5 \%$ exhibiting values greater than $10,000 \mathrm{~m}^{2}$. In this case, the standard deviation was weighted toward values of $1,000 \mathrm{~m}^{2}$ or less and was underestimated. Thus, using the standard deviation in this instance was not appropriate. Similarly, for the crossing gutter interval, $80 \%$ of the data belonged to the categories $>200 \mathrm{~m}$ or $<100 \mathrm{~m}$. Thus, two dominant categories were defined, and the distribution of this parameter affected the standard deviation considerably.

\subsection{Collapse Risk Assessment Method According to Fuzzy Theory}

The present study adopted the method of Yoshimura et al. (1995; 1996), who demonstrated the benefits of using fuzzy theory and its applicability as an assessment system adapted for this region. In particular, Yoshimura et al (1995). assessed the risk of collapse based on the ratio of the relative frequency distribution of non-collapse and collapse in each category and for each factor. Therefore, in addition to studying 33 collapse locations, we sampled 30 non-collapse locations. For the non-collapse locations, we sampled during the opening years for the associated operation-roads. The points of non-collapse are illustrated in Figure 3. After this sampling, collapse risk was assigned a numeric value between 0 and 1 based on fuzzy theory, with the probability of collapse increasing with increasing value.



Figure 3. Non-collapse point in Terasawayama Forest. 


\section{Results}

The results of the present study can be summarized as follows.

1) The value of the collapse risk was $\geq 0.5$ when the catchment area was $\geq 1000 \mathrm{~m}^{2}$, suggesting that the risk increases with catchment area (Figure 4, Table 3).

2) The natural ground angle was found to be predominantly in the range $30-39^{\circ}$ and exhibited a normal distribution. In general, the collapse risk was found to increase with increasing slope up to $37^{\circ}$, above which the risk did not change significantly (Figure 5, Table 4).

3) For the cut and fill slope height (mountain side), most values were found to be in the range 2.0-2.9 m, and this parameter exhibited a broadly normal distribution. However, in collapse areas, cut and fill slope height reached values of $5.0 \mathrm{~m}$ or more; thus, the collapse risk was greater for greater cut and fill slope height. Previous studies have recommended a slope height of $1.5 \mathrm{~m}$ as a general guideline for the construction of operation-roads. Conversely, our results suggest that the collapse risk only exceeds 0.5 for a slope height of $1.9 \mathrm{~m}$ or more (Figure 6 , Table 5).

4) Many of the slope length (mountain side) values at collapse points were in the ranges 2.0-3.9 $\mathrm{m}$ and $\geq 6.0 \mathrm{~m}$. Conversely, non-collapse locations exhibited peak values of this variable in the range $2.0-3.9 \mathrm{~m}$, indicating that collapse risk tends to increase if the slope length of the mountain side is longer (Figure 7, Table.6).

5) For slope angle (mountain side), more than $90 \%$ of the entire study area exhibited values in the range $40-69^{\circ}$. For values $\leq 55^{\circ}$ (i.e., Category-3), the collapse risk was found to increase with increasing slope angle. Conversely, slope angles in the range $56-62^{\circ}$ (Category-4) can be considered safe because the collapse risk for this category is less than 0.5 (Figure 8, Table.7).

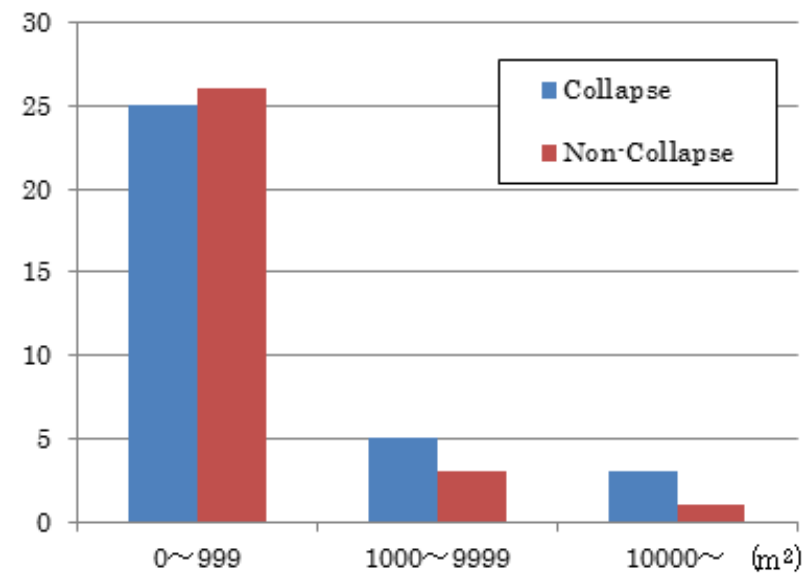

Figure 4. Frequency distribution in catchment area.

Table 3. Method of collapse risk of catchment area.

\begin{tabular}{lrrr}
\hline & Category-1 & Category-2 & Category-3 \\
\hline Catchment area $\left(\mathrm{m}^{2}\right)$ & $0-999$ & $1,000-9,999$ & $10,000-$ \\
Ratio & 0.874 & 1.515 & 2.70 \\
Collapse risk & 0.437 & 0.758 & 1.000 \\
\hline
\end{tabular}




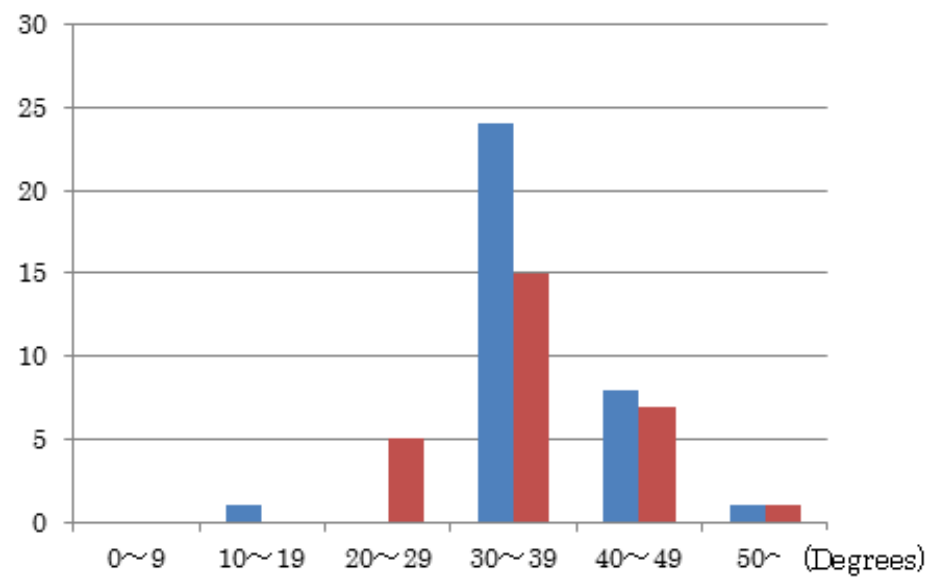

Figure 5. Frequency distribution of natural ground angle.

Table 4. Method of collapse risk of natural ground angle.

\begin{tabular}{lrrrr}
\hline & Category-1 & Category-2 & Category-3 & Category-4 \\
\hline Natural ground angle $\left(^{\circ}\right)$ & -30 & $31-36$ & $37-44$ & $45-$ \\
Ratio & 0.409 & 0.614 & 1.773 & 1.432 \\
Collapse risk & 0.205 & 0.307 & 0.886 & 0.716 \\
\hline
\end{tabular}

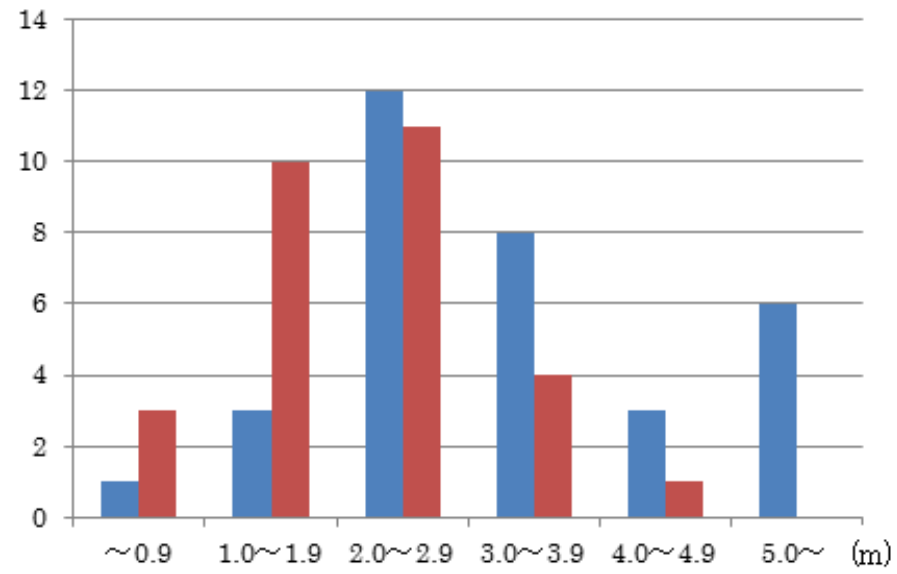

Figure 6. Frequency distribution of cut and fill slope height (mountain side).

Table 5. Method of collapse risk of cut and fill slope height (mountain side).

\begin{tabular}{lrrr}
\hline & Category-1 & Category-2 & Category-3 \\
\hline Slope height of mountain side $(\mathrm{m})$ & -1.8 & $1.9-3.5$ & $3.6-$ \\
Ratio & 0.188 & 1.113 & 9.667 \\
Collapse risk & 0.094 & 0.557 & 4.833 \\
\hline
\end{tabular}




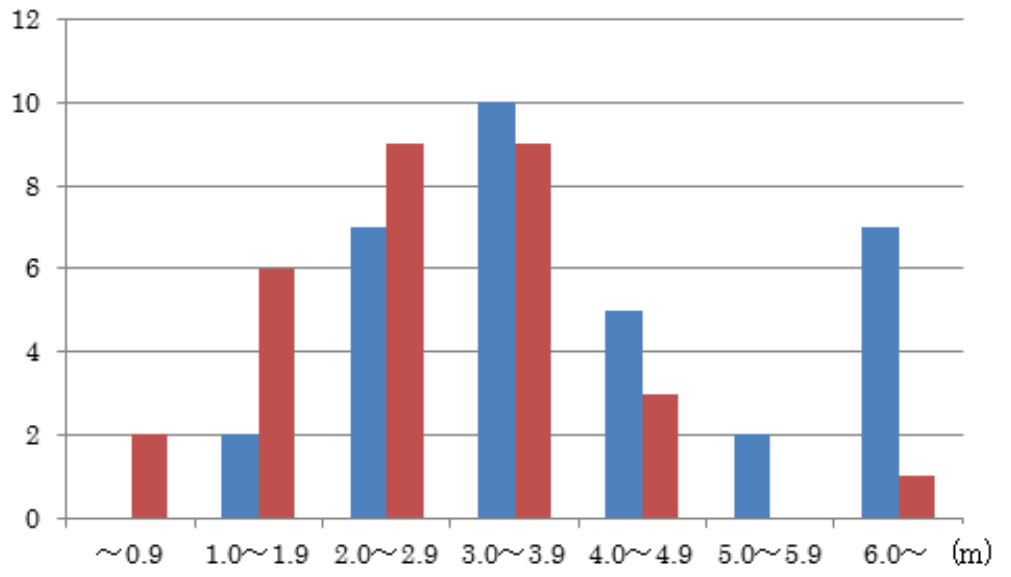

Figure 7. Frequency distribution of slope length (mountain side).

Table 6. Method of collapse risk of slope length (mountain side).

\begin{tabular}{lrrrr}
\hline & Category-1 & Category-2 & Category-3 & Category-4 \\
\hline Slope length of mountain side $(\mathrm{m})$ & -2.3 & $2.4-4.3$ & $4.4-6.3$ & $6.3-$ \\
Ratio & 0.379 & 1.023 & 2.232 & - \\
Collapse risk & 0.189 & 0.511 & 1.136 & 1.000 \\
\hline
\end{tabular}

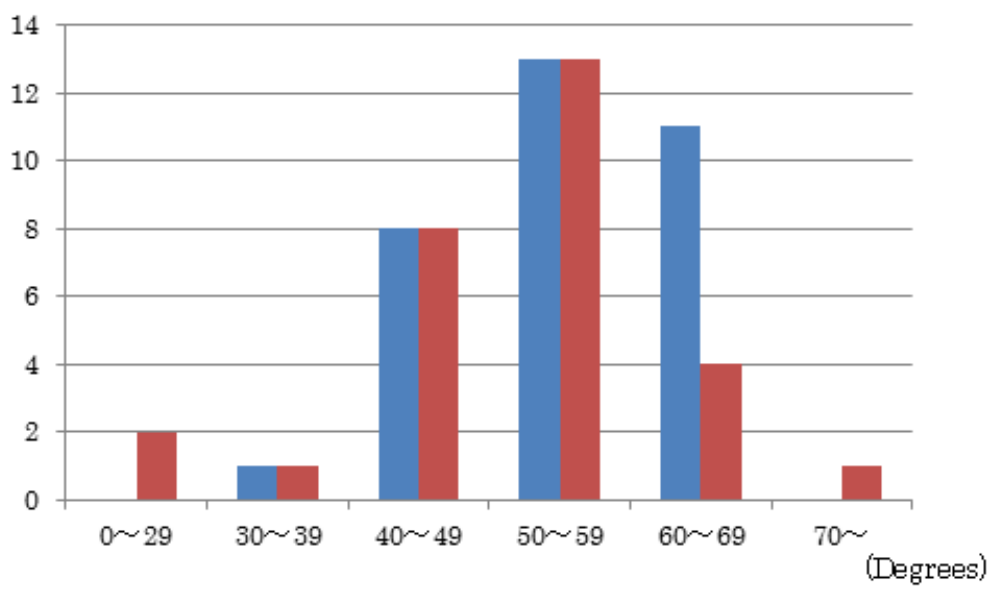

Figure 8. Frequency distribution of slope angle (mountain side).

Table 7. Method of collapse risk of slope angle (mountain side).

\begin{tabular}{lrrrrr}
\hline & Category-1 & Category-2 & Category-3 & Category-4 & Category-5 \\
\hline Slope angle of mountain side $\left(^{\circ}\right)$ & -41 & $42-48$ & $49-55$ & $56-62$ & $63-$ \\
Ratio & 0.293 & 0.502 & 1.142 & 0.879 & 1.465 \\
Collapse risk & 0.146 & 0.251 & 0.571 & 0.439 & 0.732 \\
\hline
\end{tabular}


6) For cut and fill slope height (valley side), the majority of collapse points exhibited values in the range 2.0-4.9 m, whereas the majority of the non-collapse points exhibited values of 1.0-2.9 $\mathrm{m}$. Thus, our results indicate a tendency for increased collapse risk for slope heights of $2.2 \mathrm{~m}$ or more (Figure 9, Table 8).

7) For slope length (valley side), points exhibiting values of $\geq 4.0 \mathrm{~m}$ comprise more than $70 \%$ of all collapse points. Moreover, our results show that the collapse risk increases with increasing slope length; this trend is particularly significant for lengths $\geq 3.0 \mathrm{~m}$ (Figure 10, Table 9).

8) The majority $(80 \%)$ of the studied points for slope angle (valley side) were in the range $30-49^{\circ}$. Moreover, we found the threshold between safe and unsafe slopes to be $35^{\circ}$, with a particularly pronounced collapse risk for slope angles $\geq 43^{\circ}$ (Figure 11, Table 10).

9) The majority of points studied exhibited widths in the range 3.0-3.9 $\mathrm{m}$, and width was found to exhibit a mountain-type distribution. Our results demonstrate that collapse risk is low for widths $\leq 3.0 \mathrm{~m}$ but that risk increases for widths greater than this threshold value (Figure 12, Table 11).

10) Longitudinal slope was found to exhibit a dispersed distribution, with no clear modal value. In all cases, collapse risk was in the range 0.4-0.5, with no significant variations in risk between categories (Figure 13, Table 12). Finally, (11) the crossing gutter interval was found to form two main categories, accounting for $80 \%$ of the total: $\leq 100 \mathrm{~m}$ and $\geq 201 \mathrm{~m}$. However, we were unable to determine any changes in collapse risk due to changes in installation interval (Figure 14, Table 13).

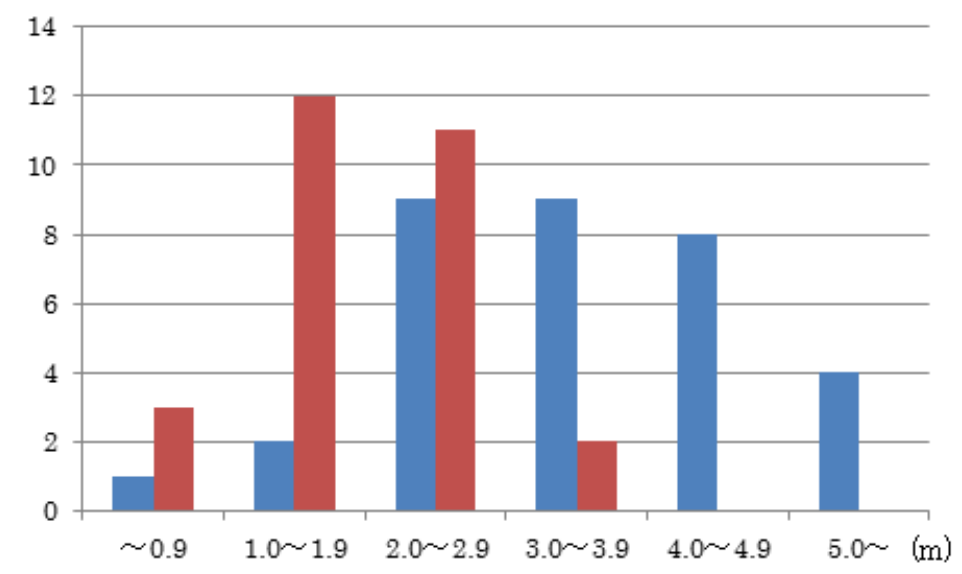

Figure 9. Frequency distribution of cut and fill slope height (valley side).

Table 8. Method of collapse risk of cut and fill slope height (valley side).

\begin{tabular}{lrrrr}
\hline & Category-1 & Category-2 & Category-3 & Category-4 \\
\hline Slope height of valley side $(\mathrm{m})$ & -1.0 & $1.1-2.1$ & $2.2-3.3$ & $3.4-$ \\
Ratio & 0.283 & 0.159 & 1.320 & 12.727 \\
Collapse risk & 0.141 & 0.080 & 0.660 & 6.364 \\
\hline
\end{tabular}




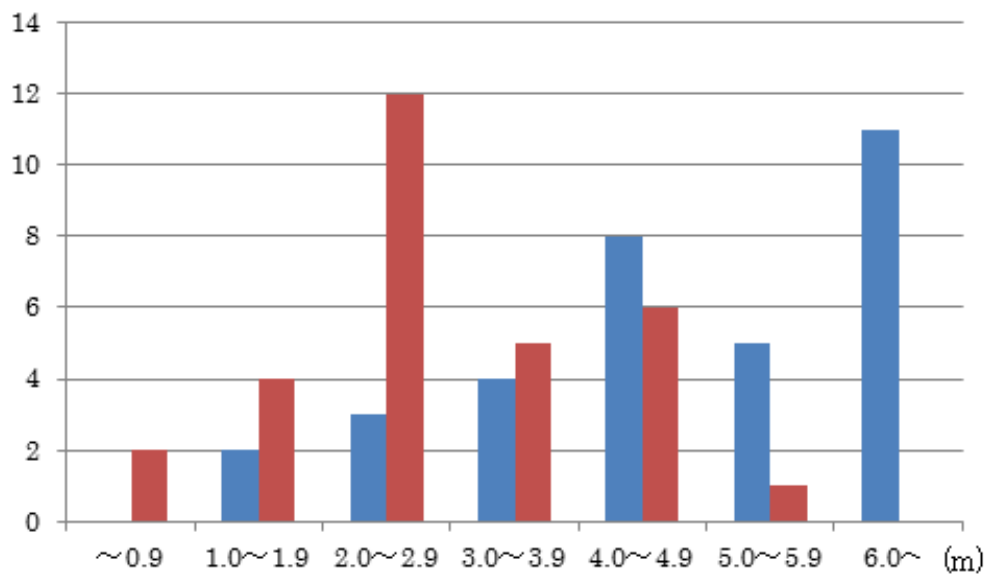

Figure 10. Frequency distribution of slope length (valley side).

Table 9. Method of collapse risk of slope length (valley side).

\begin{tabular}{lrrrr}
\hline & Category-1 & Category-2 & Category-3 & Category-4 \\
\hline Slope length of valley side $(\mathrm{m})$ & -2.9 & $3.0-5.0$ & $5.1-7.1$ & $7.2-$ \\
Ratio & 0.253 & 1.157 & 6.364 & - \\
Collapse risk & 0.126 & 0.579 & 3.182 & 1.000 \\
\hline
\end{tabular}

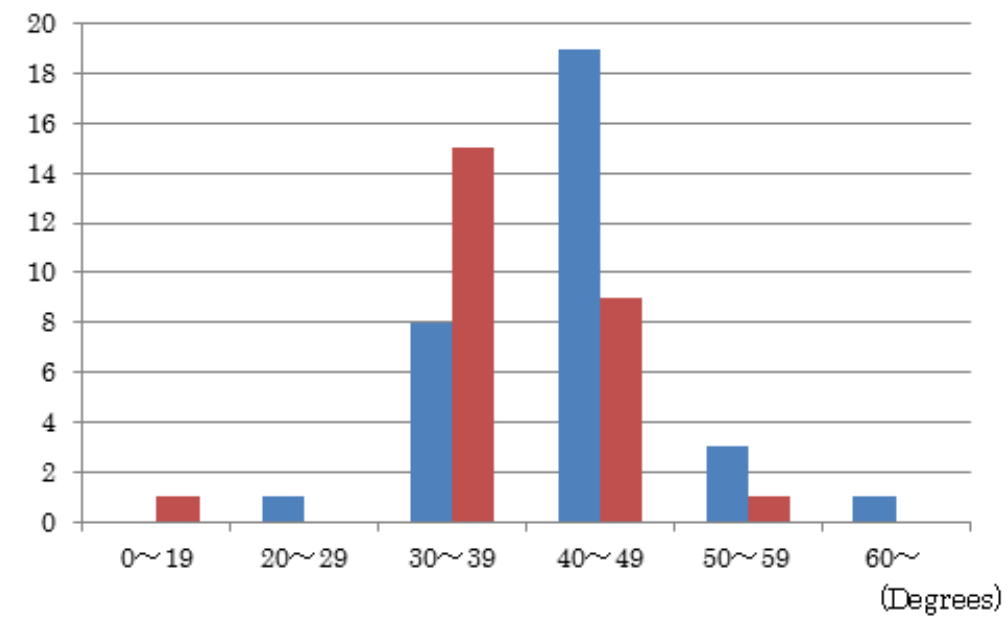

Figure 11. Frequency distribution of slope angle (valley side).

Table 10. Method of collapse risk of slope angle (valley side).

\begin{tabular}{lrrrrr}
\hline & Category-1 & Category-2 & Category-3 & Category-4 & Category-5 \\
\hline Slope angle of valley side $\left(^{\circ}\right)$ & -28 & $29-35$ & $36-42$ & $43-50$ & $50-$ \\
Ratio & 0.406 & 0.271 & 0.975 & 1.950 & 3.250 \\
Collapse risk & 0.203 & 0.135 & 0.488 & 0.975 & 1.625 \\
\hline
\end{tabular}




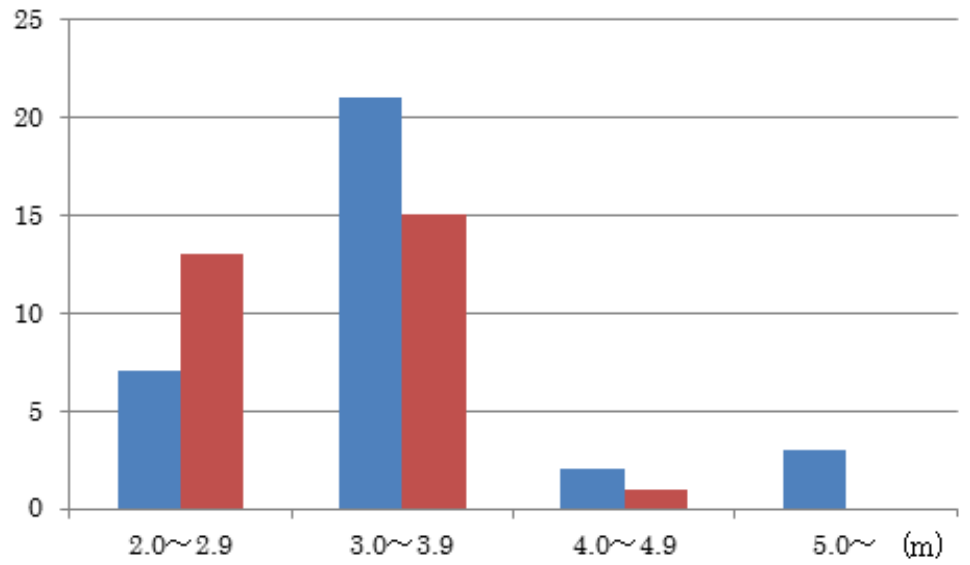

Figure 12. Frequency distribution of width.

Table 11. Method of collapse risk of width.

\begin{tabular}{lrrrr}
\hline & Category-1 & Category-2 & Category-3 & Category-4 \\
\hline Width $(\mathrm{m})$ & -3.0 & $3.1-3.5$ & $3.6-4.0$ & $4.1-$ \\
Ratio & 0.455 & 1.091 & 2.424 & 4.545 \\
Collapse risk & 0.227 & 0.545 & 1.212 & 2.273 \\
\hline
\end{tabular}

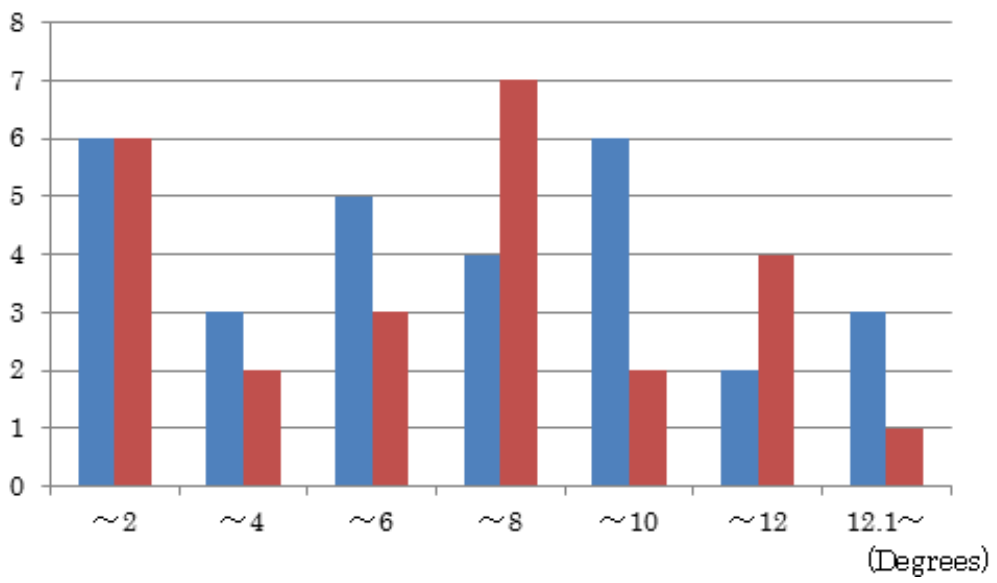

Figure 13. Frequency distribution of longitudinal slope.

Table 12. Method of collapse risk of longitudinal slope.

\begin{tabular}{lrrrr}
\hline & Category-1 & Category-2 & Category-3 & Category-4 \\
\hline Longitudinal slope (\%) & -3.3 & $3.4-7.1$ & $7.2-10.9$ & $11.0-$ \\
Ratio & 0.879 & 0.879 & 1.004 & 0.879 \\
Collapse risk & 0.439 & 0.439 & 0.502 & 0.439 \\
\hline
\end{tabular}




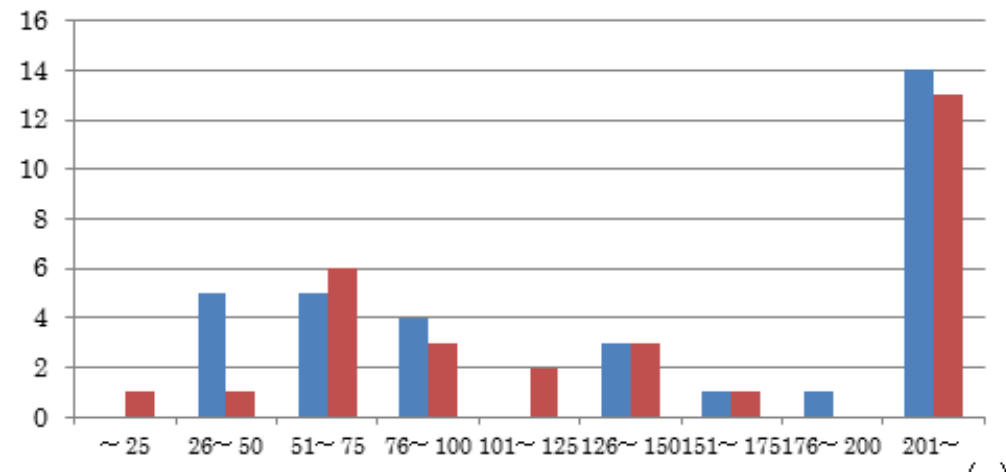

$(\mathrm{m})$

Figure 14. Frequency distribution of crossing gutter interval.

Table 13. Method of collapse risk of crossing gutter interval.

\begin{tabular}{lrrr}
\hline & Category-1 & Category-2 & Category-3 \\
\hline Crossing gutter interval $(\mathrm{m})$ & -75 & $76-200$ & $200-$ \\
Ratio & 1.136 & 0.909 & 0.979 \\
Collapse risk & 0.568 & 0.455 & 0.490 \\
\hline
\end{tabular}

\section{Discussion and Conclusions}

Based on the results of a collapse risk assessment, we were able to divide each factor studied into three characteristic groups affecting collapse, as follows. (1) For eight factors, increasing their value tended to increase the collapse risk: slope angle (valley side), slope length (mountain side and valley side), cut and fill slope height (mountain side and valley side), width, catchment area, and natural ground angle. As the majority of these factors are topographic variables, we infer that the collapse risk increases in areas with steep topography. (2) For two factors (longitudinal slope, crossing gutter interval), the collapse risk was found to remain relatively constant. However, previous studies have suggested that these factors may affect road surface scour, which was not investigated here. (3) Finally, the influence of one of the factors (slope angle, mountain side) was found to be variable depending on other factors. For example, the collapse risk was greater for the low slope angle of Category-3 than for the steeper slope of Category-4. It is thought that this may reflect the influence of factors not considered explicitly in the previous studies (e.g., geology) on collapse risk (e.g., Cheng et al., 2002).

The abovementioned results help to clarify the effects of individual collapse risk factors; however, it is also necessary to understand the relationships between these factors. Therefore, we investigated which factors exert the greatest influence on collapse risk based on mathematical quantification type II (Hayashi, 1954; 1993). This method has often been used for research of disaster prevention prediction (Kasa et al.,1992), and a collapse dangerous location judging of the Ministry of Land, Infrastructure and Transport. Mathematical quantification type II is a technique used when determining the qualitative data such influence factor higher or lower factors to collapse by using the qualitative data such as whether the high or low risk collapse. It is possible to predict the effect created determining model equation belongs to any group other than the sample from the characteristic to have a sample in mathematical quantification type II. In addition, it is possible to clarify the influence of the group classification from the model formula. This study has revealed a degree of influence on the collapse from the model equation. Using this analysis method, it is possible to create a model equation from sample characteristics and to use this to clarify the influence of various groupings. Furthermore, we replaced the collapse risk of each factor with values of 1 or 0 based on dummy variables and performed regression analysis.

It can be determined by subtracting the minimum value from the maximum value of values was 
normalized regression equation importance. We can determine the influence of the collapse is strong if value of importance is large. Based on importance analysis conducted as part of a previous study, cut slope height is the primary factor controlling collapse risk for forest roads. Typically, as cut slope height increases, the amount of excavation below the normal ground surface also increases. Under such conditions, the shear stress is increased owing to the weight of the slope, causing the operation-road to collapse (Sirabe et al., 1991). In this manner, the effects of cut slope height can overshadow the effects of other variables. That influence due to factors cut slope length and fill slope height is stronger has been determined. We considered these factors also, become unstable slope that clod weight increases in the same way as the mountain slopes high, influence has become stronger. In addition, empirical evidence exists for the relatively strong influence of catchment area on collapse risk.

Cut slope angle has been found to have the least importance for operation road collapse. "When Cut height is $1.2 \mathrm{~m}$ within about, there is a case to be cut into vertical is possible, Want to consider the basis of the soil" The Forestry Agency (2010) has provided construction guidelines for both forest and operation roads. However, the scientific evidence and empirical knowledge on which these guidelines are based is incomplete. We believe that the results presented here go some way toward rectifying this situation.

The results presented here for operation-roads can be compared with the results of similar studies conducted previously for forest roads. For example, Kondo and Kamiya (1995) determined the following factors to be important in generating forest road collapse, in decreasing order: catchment collapse area, catchment area, fill slope structure, and fill slope height. In general, two types of influential factors can be considered important: terrain factors, and road structure factors. For operation-roads, we found the geometric structure to be the primary factor controlling collapse risk; conversely, for forest roads, terrain factors were determined to be more influential. We believe this to reflect the fact that forest roads are typically designed with emphasis on strengthening of the road body and structural protection of associated slopes; thus, the geometric factors can be largely eliminated. However, such mitigation of collapse risk typically comes at a cost that is unfeasible for operation-roads, such that the collapse risk associated with geometric factor remains considerable. In future, it may be possible to implement measures to reduce the risk of collapse by mitigating the effects of geometric structure factors during the construction of operation-roads.

\section{References}

Cheng, P., Goto, J., and Zhan, W. (2002) Assessing the stability of cut slopes by using soil profile pattern classification. J. Jpn. Forest Eng. Soc. 17: 3-14 (in Japanese with English Summary).

Forestry Agency (2010). Operation road construction guidelines. < http://www.rinya.maff.go.jp/j /seibi/saisei/pdf/sinrinsagyoudou.pdf > (Accessed 1 August 2014) (in Japanese).

Hayashi, C. (1954) Multidimensional quantification, II. Proc. Japan Acad. Volume 30, Number 3: 165-169.

Hayashi, C. (1993) Multidimensional quantification. - Sociological Theory and Methods- Asakura syoten, pp233 (in Japanese).

Kasa, H., Kurodai, M., Obayashi, S., Kojima, H. (1992) On the Applicability of Remote Sensing Data for Landslide Prediction Model. J. Remote Sensing Society of Japan 12: 5-15 (in Japanese with English Summary)

Kondo, K., and Kamiya, N. (1995) The analysis on the factors of forest road disasters in the area of Southern Akaishi Mountains. J. Jpn. Forest Eng. Soc. 10: 205-212 (in Japanese with English Summary).

Sirabe, S., Kutara, K., Iseda, T., and Tanahashi, Y. (1991) Study on rainwater infiltration characteristics and slope stability. Faculty of Engineering, Nagasaki University. 20: 53-60 (in Japanese with English Summary).

Suzuki, Y., and Yamauchi, K. (2000) Practical investigation on affiliate structures for prevention of disaster and degradation on low-standard forest roads. J. Jpn. Forest Eng. Soc. 15: 113-124 (in Japanese with English Summary). 
Yoshimura, T., Akahane, G., and Kanzaki, K. (1995) The evaluation of potential slope failure of forest roads using the fuzzy theory. J. Jpn. Forest Eng. Soc. 10: 195-204 (in Japanese with English Summary).

Yoshimura, T., Akahane, G., Miyazaki, H., and Kanzaki, K. (1996) The evaluation of potential slope failure of forest roads using the fuzzy integral: Testing the discriminant model. J. Jpn. Forest Eng. Soc. 11: 165-172 (in Japanese with English Summary). 